\title{
Cooking fuels and sustainable social development: the case of Africa
}

\author{
Ifeoluwa Garba \\ Department of Electrical and Electronics Engineering \\ University of Strathclyde \\ Glasgow, United Kingdom \\ ife.garba@strath.ac.uk
}

\begin{abstract}
Access to energy is vital in addressing many of the current global sustainable development adversities that continue to impact on people's economic, social and physical well-being. Despite the expanding attention from national and international governments, agencies and academics, energy poverty remains a reality for millions of people living in Africa. As a whole, the African energy sector is described to be the most impoverished part of the global energy system. The aim of this paper is to review the challenges and opportunities of the African energy system: focusing on the most demanded, yet, most overlooked energy service - cooking. In addition, it presents empirical results illustrating the effects of the inaccessibility to modern cooking fuels on aspects of sustainable social development: using the panel data of the African region.
\end{abstract}

Index Terms-Access, Challenges, Energy poverty, Impacts, Policies.

\section{INTRODUCTION}

Improving access to energy services for households in Africa remains one of the most crucial challenges faced in the region. However, the inaccessibility to modern energy services as well as the reliance of households on traditional ${ }^{1}$ energy forms continues to contribute to the hindrance of sustainable development across the region [1].

Accessibility of modern solutions of energy is vital for not only urbanisation and industrialisation: crucial factors for economic growth, but also, for sustainable social development. Yet, Africa remains the region with the largest population living without access to electricity and has the second largest population living without access to modern cooking fuels. The past two decades have seen efforts being directed towards expanding the energy systems within the region: resulting in an electricity access growth of approximately $18 \%$ over the period. However, due to the lack of efforts dedicated to improving access to modern cooking energy forms, accessibility to modern cooking forms grew less than $3 \%$ over the same period. This disregards of this aspect of energy poverty can be further exemplified by governmental goals and documents: national and international alike; which tend to address electricity accessibility yet overlook accessibility to modern cooking fuels.

The $\mathrm{PhD}$ project which has produced this paper is funded by the Engineering and Physical Sciences Research Council (EPSRC)

${ }^{1}$ Here, traditional refers to solid fuels such as Animal dung, Charcoal, Wood, etc.
What's more, there is currently a significant gap in literature looking at the effects of inaccessibility to modern cooking energy forms on sustainable social and economic development. Moreover, the limited existing literature have focused primarily on the environmental effects of inaccessibility to modern energy forms; placing little-to-no emphasis on the socio-economic effects. At most, studies have acknowledged the effects on health, with no empirical studies investigating other social aspects.

Therefore, in this paper, in addition to presenting the broader energy issues within the region, we contribute to existing literature in two-fold. Firstly, we review the embryonic literature on the challenges of access to modern cooking energy forms: in the context of Africa. Secondly, we provide empirical evidence of the effects of inaccessibility to modern cooking fuels on some sustainable development indicators for Africa. We examine the interaction relating to the use of traditional cooking fuels and enrolment in primary school; employment; labour force participation and life expectancy ${ }^{2}$.

\section{BROADER VIEW OF ENERGY ISSUES IN AFRICA}

The under-developed nature of electricity grids and nearabsent modern energy systems for cooking and/or heating, are attributing factors to the energy situation in Africa. Although the continent as a whole, crucially needs energy system development, the severity of the energy situation drastically varies across the region. Figures $1 \mathrm{a}$ and $1 \mathrm{~b}$ present the distribution of access rates across the region.

The north of Africa; with the exception of Algeria and Egypt, is close to achieving universal access whilst only islands, such as Mauritius (99.2\%), Seychelles (99.5\%) and Cape Verde $(90.2 \%)$ are progressing towards universal access. Besides these countries, the other parts of the region especially subSaharan Africa, show very poor levels of electricity access. Yet, the electricity problem across the continent goes beyond accessibility. Even in countries with improved accessibility such as South Africa, there have been reports of deterioration in supply reliability and price increase [2]. When considering modern energy forms for cooking and/or heating (or cooling), the accessibility issues become more severe. Across the region, only a few countries have above $45 \%$ access level.

\footnotetext{
${ }^{2}$ Part of the indicators used in the United Nations Sustainable Development Goals (SDG)
} 

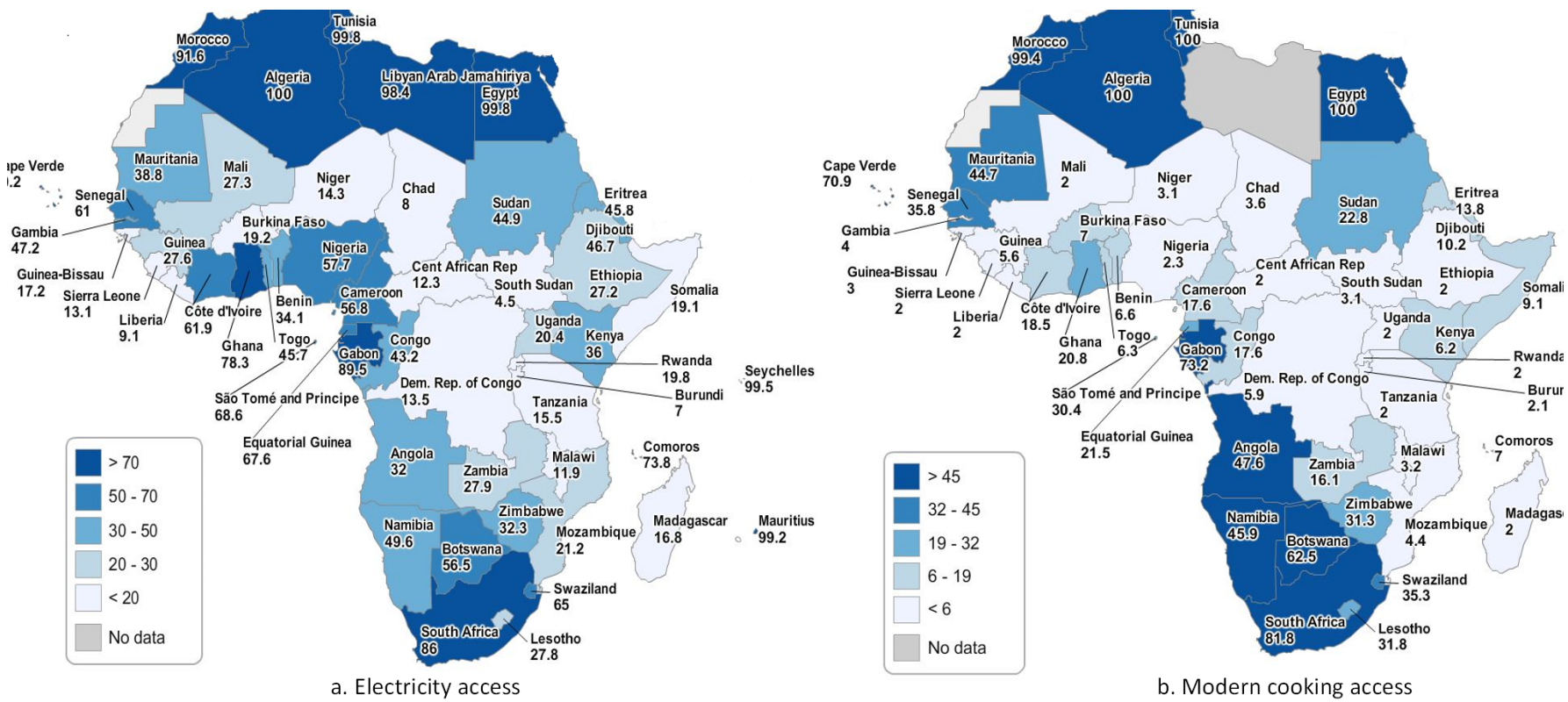

Fig. 1. Access rates across Africa

From a broader perspective, it is striking that energy consumption in Africa, a region with almost $17 \%$ of the world population, accounts for only $6 \%$ of the energy used across the globe consumption. What's more, the energy mix within the region is heavily undiversified. Yet, despite the low energy consumption levels, the region accounts for almost $30 \%$ of the overall biofuels consumed in the world ${ }^{3}$. In 2016, biofuels and biowastes consumption attributed to over $50 \%$ of the total energy used within the region [1], [3], [4]. Considering only sub-Saharan Africa, this share increased to approximately $70 \%$; rising to roughly $80 \%$ when South Africa is excluded. Taken together, for a region which accounts for only $4 \%$ of the total energy consumed globally, consuming almost a third of overall global biofuels and biowastes is truly symbolic and highlights a significant variance in energy mix in the region. The implication of this major lack of diversification in energy mix converts to the observed substantial dependence on solid fuels within households in the region.

To clarify: of the approximated 377 'Million tonnes of oil equivalent' (Mtoe) of traditional biomass utilised in Africa [5] (280 'Mtoe' in Sub-Sahara) in 2016, approximately $90 \%$ was used by households. Moreover, cooking accounted for more than $80 \%$ of the total energy utilized in households. With traditional sources like fire-wood, straw and dried animal wastes usually being the dominant fuel forms utilized within the region [6]. Yet, a large amount of these are generally unprocessed and in many instances, simultaneously utilized with makeshift, ineffectual, traditional cook-stoves. Hence, bringing about consequential economic, social and health effects.

The factors surrounding the substantial dependence on solid fuels for cooking are multidimensional and differ vastly

\footnotetext{
${ }^{3}$ See [1] regarding a breakdown of these figures
}

throughout Africa. Inaccessibility, unreliability and unaffordability being a few of these reasons. Notwithstanding, estimates show that in the next two (2) decades, if present policies remain unchanged, there will be limited if any, advancement in the issue [4]. Consequently, it has been anticipated that through 2030 , although the region possesses ample energy resources to satisfy its energy demand, there is the possibility of a growth in the proportion of population across the region, depending on traditional cooking fuels [6].

\section{Challenges}

Due to population growth and in some cases, economic expansions, energy demand in Africa is exponentially increasing. Nevertheless, these heightening demands would remain unfulfilled due to temporally and spatially varying factors.

Studies indicate the deficiency of infrastructure; deficiency of policies; financial barriers (at national and households levels) as well as a prevailing deficiency in attention at household and national levels, to be the ubiquitous contributing factors across the region [1], [6], [7]. Although behavioural, cultural and/or socio-economic components undoubtedly contribute to the energy issues, here, we concentrate on only the factors exterior to households and thus outside their control. However, even though these determinants are separately discussed, they are undeniably, quite interconnected.

\section{Infrastructure}

The rudimentary or in some cases, completely absent nature of the infrastructures constituting the African energy system can be termed the principal barrier to the distribution of modern energy forms for cooking and/or heating [8]. At national levels, the significance of the inadequacy in energy systems become more evident - particularly in rural areas. For most African countries, the pervasive absence of distribution 
networks (especially in rural areas) contributes to the high levels of inaccessibility to modern energy alternatives [9]. This case is further demonstrated by studies which have related the higher levels of accessibility to modern energy alternatives found in urban areas, to the presence of adequate infrastructures in the area [8], [10].

Equivalently, inadequate transportation infrastructures; particularly roads, have been shown to hinder accessibility to modern fuel alternatives in some parts of Africa [11]. To exemplify, in sub-Saharan Africa, reports show that just over $10 \%$ of roads in rural areas are paved [12]. Consequently, it can be anticipated that albeit the provision of modern fuel alternatives, high transportation prices remain imminent [13]. These costs would inevitably be directed to consumers. In addition to inaccessibility and unaffordability, deficient transportation infrastructures could be linked to the unreliability aspect of the energy issue in Africa. To exemplify, Fukubayashi and Kimura in their insightful study, reported that in most rural areas in Africa, during rainy season, the areas become inaccessible owing to poor roads [14]. The significance of adequate transportation infrastructure can be considered as two-fold.

Considering the cost perspective, the shortage in supply would ensue increased demand which would be left unmet due to reduced supply. In turn, this would cause a change in the equilibruim cost of energy [15] which ultimately turns to greater purchase price for purchasers. Finally, the effects of accessibility and reliability of energy sources on households have been extensively analysed in literature [16], [17]. The evidences presented by these studies indicate that reliability of energy supply acts as a determinant of households' energy sources [18], [19]. Therefore, from the demand perspective, unreliability and insecurity of modern energy supply may possibly discourage households from converting to modern alternatives.

\section{Finance}

Financial barriers significantly impacts on both the supply and demand aspects of accessibility to modern energy sources. From a supply perspective, it can be anticipated that financial restrictions would impact on the potentialities of infrastructure development - infrastructures necessary for adequate energy supply.

From a consumers' perspective, as a result of high energy costs, households are discouraged from shifting towards modern forms of energy. Based on the study by Jeuland et.al [20], table I illustrates the various costs related to the different cooking forms. The 'investment costs' are illustrated using the estimated mid-values whilst the 'fuel costs' and 'consumption per household' are presented using the ranging estimates. In the case of investment costs, the traditional fuelwood and biogas digester options, have the lowest and highest investment costs, respectively. For traditional woodfuel, it is hypothesised that households can either gather or have a low purchasing cost for wood and require no special appliance [21]. However, although in the long run, the traditional woodfuel involves the highest utilization of fuel; looking through a present-day cost viewpoint, the low fuel prices as well as low investment costs make traditional or modern 'fuelwood', an appealing energy source for many households in rural Africa [21]. Excluding 'LPG' and 'Kerosene', the towering investment costs related to substitute energy forms such as 'electricity' stoves, can be assumed to hinder the attainability of households switching to these options.

The implications of these costs are further heightened given that poverty rates are high across these regions with high energy inaccessibility levels [22]. The results from the household survey by Energy Sector Management Assistance Program (ESMAP) further illustrates the effects of financial barriers. Due to high costs, approximately $60 \%$ of households in Africa can not afford to change from traditional fuel forms to modern cooking alternatives [21]. In addition to high investment costs, high fuel prices for energy alternatives such as LPG and Electricity, might also deter households wanting to move onto these options.

TABLE I

COSTS ASSOCIATED TO VARIOUS COOKING OPTIONS [20]

\begin{tabular}{lllc}
\hline \hline & $\begin{array}{l}\text { Invest- } \\
\text { ment cost } \\
(\$)\end{array}$ & $\begin{array}{l}\text { Fuel } \\
\text { cost } \\
(\$ / \mathrm{kg})\end{array}$ & $\begin{array}{c}\text { Consumption per } \\
\text { household (toe/year) }\end{array}$ \\
\hline Traditional cookstoves & $3-6$ & $0.1-0.8$ & $0.5-1.9$ \\
Charcoal & $0-2$ & $0.03-$ & $1.0-3.7$ \\
Fuelwood, straw & 0.2 & $0.4-1.5$ \\
\hline Improved cookstoves & 14 & $0.1-0.8$ & $0.5-1.6$ \\
Charcoal & 15 & $0.03-$ & $0.1-0.2$ \\
Fuelwood & & 0.2 & $0.08-0.15$ \\
& 30 & $0.3-0.7$ & $0.07-0.13$ \\
Alternative cookstoves & 60 & $0.4-1.0$ & $0.07-0.14$ \\
Kerosene & 300 & $0.03-$ & \\
LPG & & 0.10 & \\
Electricity & $600-$ & & \\
Biogas digester & 1,500 & & \\
\hline \hline
\end{tabular}

\section{EFFECTS AND IMPACTS}

To provide empirical evidence of the effects of inaccessibility of modern energy on development in Africa, we employ panel regression methods and panel data of 47 sub-Saharan Africa countries; over the period of 2000 to 2015 . With respect to the aspects of development considered, we analyse impacts on education, employment, labour force participation and life expectancy. These act as indicator of the principal objectives of the United Nation's (UN) Sustainable Development Goal (SDG) [22]. The roles of education and employment in the development of countries is fairly established. Studies such as Klasen [23], Hanushek [24], [25] have demonstrated that the literacy level of a country is linked to individual income, income distribution and ultimately, economic development within the country.

Consequently, to capture the effect of inaccessibility at individual and national levels, we apply these variables as 
TABLE II

EFFECTS OF INACCESSIBILITY OF MODERN ENERGY ON PRIMARY EDUCATION.

\begin{tabular}{llll}
\hline \hline & \multicolumn{3}{c}{ Primary Education enrolment } \\
& \multicolumn{3}{c}{ Models } \\
\cline { 2 - 4 } & Fixed effects & Between effects & Random effects \\
\hline Coefficient & -0.5466 & -0.3522 & -0.4062 \\
Std. Error & 0.1666 & 0.1033 & 0.0878 \\
$\mathrm{t}$ - Statistics & -3.2800 & -3.4100 & -4.6300 \\
$p$ value & 0.0010 & 0.0030 & 0.0000 \\
\hline \hline
\end{tabular}

explanatory variables. Finally, to provide a comprehensive analysis, although some literature have considered the impacts of the traditional fuel use on indoor pollution, an analysis of the inaccessibility to modern energy on health: using life expectancy as our explanatory variable is performed. For our 'solid' variable, we use data on 'access to clean cooking fuels and technology' as proxy. Yet, it is important to note that as discussed in section III, even with access to modern energy forms, some households would still utilise traditional energy alternatives. Consequently, there is the possibility of inconsequential imperfection in the variable. For the analyses, we design three bivariate estimator models: fixed effects, between effects and random effects models. The fixed effects models estimate the effects of inaccessibility within the regions. The between effects models estimate the effects within the countries in Africa whilst the random effects models estimate the effects within and/or across countries as well as across the period.

The results from the analyses are presented in tables II, III, IV and V. With the exception of the 'employment fixed effects', 'labour force fixed effects' and 'random effects', all models have significant coefficients and p-values. Nonetheless, we employ the Lagrange multiplier and Hausman tests to determine the most efficient models. To interpret the results,

TABLE III

EFFECTS OF INACCESSIBILITY OF MODERN ENERGY ON EMPLOYMENT.

\begin{tabular}{llll}
\hline \hline & \multicolumn{2}{c}{$\begin{array}{c}\text { Employment of population } \\
\text { Models }\end{array}$} \\
\cline { 2 - 4 } & Fixed effects & Between effects & Random effects \\
\hline Coefficient & -0.0788 & 0.3013 & -0.0361 \\
Std. Error & 0.0263 & 0.0740 & 0.0252 \\
$\mathrm{t}-$ Statistics & -3.0000 & 4.0700 & -1.4400 \\
$p$ value & 0.0030 & 0.0000 & 0.1510 \\
\hline \hline
\end{tabular}

TABLE IV

EFFECTS OF INACCESSIBILITY OF MODERN ENERGY ON LIFE EXPECTANCY.

\begin{tabular}{llll}
\hline \hline & \multicolumn{3}{c}{ Life expectancy } \\
& \multicolumn{3}{c}{ Models } \\
\cline { 2 - 4 } & Fixed effects & Between effects & Random effects \\
\hline Coefficient & -0.5391 & -0.1148 & -0.3077 \\
Std. Error & 0.0351 & 0.0321 & 0.0249 \\
$\mathrm{t}$ - Statistics & -15.3600 & -3.5800 & -12.3700 \\
$p$ value & 0.0000 & 0.0010 & 0.0000 \\
\hline \hline
\end{tabular}

TABLE V

EFFECTS OF INACCESSIBILITY OF MODERN ENERGY ON LABOUR FORCE PARTICIPATION.

\begin{tabular}{llll}
\hline \hline & \multicolumn{2}{c}{$\begin{array}{c}\text { Labour force participation } \\
\text { Models }\end{array}$} \\
\cline { 2 - 4 } & Fixed effects & Between effects & Random effects \\
\hline Coefficient & 0.0075 & 0.2159 & 0.0258 \\
Std. Error & 0.0223 & 0.0719 & 0.0214 \\
$\mathrm{t}$ - Statistics & 0.3400 & 3.000 & 1.2100 \\
$p$ value & 0.7350 & 0.0040 & 0.0228 \\
\hline \hline
\end{tabular}

we focus primarily on the coefficients and $p$ values.

The coefficients show the expected marginal change(s) in dependent variable due to a unit change in the independent variable. The $\mathrm{P}$ values are based on the null hypothesis $\left(H_{0}\right)$; Coeff $=0$. Therefore, to reject the null hypothesis of no correlation between independent and dependent variables, $p$ value must be less than $0.05(5 \%)$.

In tables II, across all models, there results obtained demonstrate that inaccessibility of modern energy has significant effects on primary education. Across all models, a unit increase in inaccessibility results in a significant decrease in primary school enrolment across children in the region. The study by the IEA which reports that women and children in Africa spend up to 7 hours daily on cooking activities due to inefficient energy forms [6], would further demonstrate the implication of effect.

Table III shows the effects on employment. It is interesting the results indicate that within countries, there is a negative and significant effect of inaccessibility on employment. Further, the random effect model indicated that there is a negative but non-significant effect whilst the between model shows a positive but significant effect across countries. Following the Lagrange multiplier test, we disregard the between model as less significant.

Across all models in Table IV, we obtain negative and significant effects on life expectancy. These results are in agreement with studies which demonstrate the role of solid fuels in respiratory diseases (see [26]).

Finally, the results on labour force participation presented in Table $\mathrm{V}$ show positive and with the exception of the fixed effects model, significant effects.

\section{DISCUSSION AND CONCLUSION}

This paper has discussed the energy issue across Africa, the challenges to accessibility faced by the region as well as the effects of inaccessibility of principal sustainable development indicators.

Although at varying degrees, the results obtained from the analyses show that inaccessibility to modern energy forms has a significant effect on all investigated indicators. With the exclusion of the labour force participation models, where positive effects were obtained, all models imply that inaccessibility to modern energy forms produces a negative impact on education, employment and life expectancy. In some cases, a unit decrease in accessibility is seen to produce up to 0.55 
unit decrease in outcome. To exemplify, from these results, it is observed that an increase in inaccessibility to modern energy forms produces a considerable decline in the likelihood of the enrolment of children in primary schools. This absence of education can be anticipated to bring about factors such as prominent illiteracy, deficit of educated professionals in the labour force, to name a few, which act as determinants to lack of socio-economic development. Thus, the significance of these obtained results are consequential.

More focus ought to be placed on the subject of inaccessibility to modern energy in Africa. Importantly, a more comprehensive perception of the situation and the primary contributing components are essential to aid the development of effective solutions. On this basis, in this paper, we have briefly reviewed the challenges common to countries across the region. However, it is fundamental to realise there are cultural, social and geographical challenges that ought to be taken into account if the problem is to be effectively addressed. For example, a potential starting point for tackling the issue is the establishment of national databases which give elaborate and adequate details on the issue - including extensive details on energy profiles of households. To clarify, the extensive lack of data on energy patterns means that policies which support energy conservation, cannot be considered. In fact, without these information, national energy demand can not be estimated. In terms of cooking energy sources, without data showing the stoves types used by households; fuel types utilised for cooking; cost components; to name a few, an adequate understanding of the problem would be impossible. Furthermore, data on potential fuel sources; stoves types; cost analyses; estimates of the ability and willingness to pay, as a function of income; could provide policy-makers with crucial details necessary for the development of more efficacious policies which could address the staggering inaccessibility figures.

To address infrastructure challenges, asides developing and enhancing energy grids and fundamental infrastructures in Africa, a worthwhile approach could be to develop small-scale community energy centres - using a distributed generation approach. This approach could be particularly advantageous in areas where lacking infrastructures like roads, may possibly physically and/or financially, impede development of energy infrastructures.

Finally, to tackle financial challenges: particularly in areas with low or in some cases, volatile income, financial assistance such as subsidies, grants, amongst others, would be necessary to help impoverished households climb onto the modern energy 'ladder'. Additionally, policies aimed at addressing energy poverty in Africa, must be designed in such a way that they align with more extensive policies designed to alleviate income poverty and promote economic development.

\section{REFERENCES}

[1] I. Garba and R. Bellingham, "The Impact of Lack of Clean Cooking Fuels on Sustainable Development in Developing Countries," in ASME 2018 12th International Conference on Energy Sustainability, (Lake Buena Vista), pp. 1-8, ASME, 2018.
[2] International Energy Agency (IEA), "Africa Energy Outlook: A focus on prospects in sub-Saharan Africa," tech. rep., International Energy Agency (IEA), Paris, 2014.

[3] The World Bank, "World development indicators," 2017.

[4] United Nations, "Work of the Statistical Commission pertaining to the 2030 Agenda for Sustainable Development," 2017.

[5] International Energy Agency (IEA), International Atomic Energy Agency(IAEA), "Energy indicators for sustainable development: Guidelines and methodologies," tech. rep., International Energy Agency (IEA), United Nations department of economic and social affairs, Vienna, 2007.

[6] International Energy Agency, "Energy for cooking in developing countries," World Energy Outlook 2006, pp. 419-445, 2015.

[7] World Bank Group, "Clean and Improved Cooking in Sub-Saharan Africa," Tech. Rep. 98664, World Bank Group, Washington DC, 2014.

[8] N. G. Bruce, K. Aunan, and E. A. Rehfuess, "Materials on development financing." 2017.

[9] S. C. Bhattacharyya, Energy Access and Development. John Wiley and Sons, Ltd., Publication, first edit ed., 2013.

[10] S. Malla and G. R. Timilsina, "Household cooking fuel choice and adoption of improved cookstoves in Developing Countries: a review." 2014.

[11] World Bank Group, "Clean and improved cooking in sub-Saharan Africa," Tech. Rep. 98664, World Bank Group, Washington DC, 2014.

[12] S. L. Nkomo, S. Desai, and K. Peerbhay, "Assessing the conditions of rural road networks in South Africa using visual observations and fieldbased manual measurements: A case study of four rural communities in Kwa-Zulu Natal," Review of Social Sciences, vol. 1, no. 2, 2016.

[13] S. R. Khandker, Z. Bakht, and G. B. Koolwal, "The poverty impact of rural roads: Evidence from bangladesh," Economic Development and Cultural Change, vol. 57, no. 4, pp. 685-722, 2009.

[14] Y. Fukubayashi and M. Kimura, "Improvement of rural access roads in developing countries with initiative for self-reliance of communities," Soils and Foundations, vol. 54, no. 1, pp. 23 - 35, 2014. Special Issue on 2nd International Conference on Transportation Geotechnics IS-Hokkaido2012.

[15] R. Baldick, R. Grant, and E. Kahn, "Linear Supply Function Equilibrium: Generalizations, Application, and Limitations," no. PWP-078, 2000.

[16] W. Akpalu, I. Dasmani, and P. B. Aglobitse, "Demand for cooking fuels in a developing country: To what extent do taste and preferences matter?," Energy Policy, vol. 39, no. 10, pp. 6525 - 6531, 2011. Sustainability of biofuels.

[17] S. C. Bhattacharyya, "Energy access programmes and sustainable development: A critical review and analysis," Energy for Sustainable Development, vol. 16 , no. 3, pp. 260 - 271, 2012.

[18] D. Palit and S. C. Bhattacharyya, "Adoption of cleaner cookstoves: barriers and way forward - Debajit Palit," Tech. Rep. 64, 2014.

[19] Sustainable Energy for All (Se4All), "Sustainable Energy for All advisory board update on the Se4All high impact opportunity: Se4All Hio universal adoption of clean cooking solutions," Tech. Rep. May, Global Alliance for Clean Cookestoves, New York, 2015.

[20] M. A. Jeuland and S. K. Pattanayak, "Benefits and costs of improved cookstoves: Assessing the implications of variability in health, forest and climate impacts," PLOS ONE, vol. 7, no. 2, 2012.

[21] Energy Sector Management Assistance Program (ESMAP); Global Alliance for Clean Cookstoves (Alliance), "The state of the global clean and improved cooking sector," tech. rep., Energy Sector Management Assistance Program (ESMAP); Global Alliance for Clean Cookstoves (Alliance), Washington DC, 2015.

[22] World Bank Group, "World Development Indicators," tech. rep., World Bank Group (WB), Washington DC, 2016.

[23] S. Klasen and F. Lamanna, "The impact of gender inequality in education and employment on economic growth: New evidence for a panel of countries," Feminist Economics, vol. 15, no. 3, pp. 91-132, 2009.

[24] E. A. Hanushek, L. Woessmann, E. A. Jamison, and D. T. Jamison, "Education and economic growth," Education Next, vol. 8, Spring 2008. Name - Organization for Economic Cooperation and Development; Copyright - Copyright Education Next Spring 2008; Last updated - 201711-20; SubjectsTermNotLitGenreText - United States-US

[25] E. Hanushek and L. Wößmann, "The role of education quality in economic growth: The role of school improvement in economic development." 2007.

[26] B. Furlow, "Increasing scrutiny for the health hazards of indoor air," The Lancet Respiratory Medicine, vol. 4, no. 9, p. 690, 2016. 